Grundlagen der Kommunikation und Kognition Foundations of Communication and Cognition Bibliotheksausgabe/Library Edition

Herausgeber/Editors

Roland Posner, Georg Meggle 



\section{Status Change of Languages}

Edited by Ulrich Ammon and Marlis Hellinger

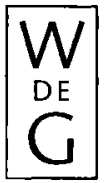

Walter de Gruyter - Berlin - New York 1992 
(0) Gedruckt auf säurefreiem Papier, das die US-ANSI-Norm über Haltbarkeit erfüllt.

\section{Library of Congress Cataloguing-in-Publication Data}

Status change of languages / edited by Ulrich Ammon and Marlis Hellinger.

p. cm. - (Foundations of communication and cognition)

Includes bibliographical references and index.

ISBN 3-11-012668-0

1. Sociolinguistics. 2. Linguistic change - Social aspects.

3. Language and languages - Variation. 4. Language and languages

- Political aspects. I. Ammon, Ulrich. II. Hellinger, Marlis.

III.Series.

P405.L54S7 1991

$306.4^{\prime} 4-\mathrm{dc} 20$

Status change of languages / ed. by Ulrich Ammon and Marlis

Hellinger. - Library ed. - Berlin ; New York : de Gruyter, 1991

(Foundations of communication and cognition)

ISBN 3-11-012668-0

NE: Ammon, Ulrich [Hrsg.]

(C) Copyright 1991 by Walter de Gruyter \& Co., D-1000 Berlin 30

Dieses Werk einschließlich aller seiner Teile ist urheberrechtlich geschützt. Jede Verwertung außerhalb der engen Grenzen des Urheberrechtsgesetzes ist ohne Zustimmung des Verlages unzulässig und strafbar. Das gilt insbesondere für Vervielfältigungen, Übersetzungen, Mikroverfilmungen und die Einspeicherung und Verarbeitung in elektronischen Systemen.

Printed in Germany

Satz und Druck: Arthur Collignon GmbH, Berlin

Buchbinderische Verarbeitung: Lüderitz \& Bauer GmbH, Berlin 